\title{
"Why are you here?" \\ A hearing instructor's journey into a deaf community of practice and discussions of family language policies
}

\author{
ISSN 2657-9774; https://doi.org/10.36534/erlj.2021.02.09 \\ Tijana Hirsch*, Orly Kayam** \\ *Wingate Academic College; tijana-h@wincol.ac.il \\ **Wingate Academic College; orlyka@wincol.ac.il
}

\begin{abstract}
Informed by the sociocultural theory on learning and approached as an ethnographic logic of inquiry, the aim of this telling case study is to explore and share the experiences of a hearing educator's socialization into a deaf community of practice within Gallaudet - the only institution of higher learning in the world for the deaf and the hard of hearing students, her consequent teaching beliefs, her family language polices (FLPS) ${ }^{12}$ and what she has learned about FLPs of the families she worked with. By drawing on different disciplines the purpose of our explorations is to contribute to the inclusion of 1) sign languages in the discussions on bilingualism, language learning and teaching, linguistic diversity, and 2) FLPS within deaf communities in the study of FLP. Following the presentation of the participant's journey into and within the deaf community, we turn to her FLP and the knowledge she has acquired regarding FLPS of families with deaf family members. We conclude with discussions on access and inclusivity within the mainstream institutions of higher learning and include some questions for further inquiry and suggestions for supporting inclusivity. It is important to note here, that this study focuses on a hearing instructor and not on deaf individuals. This is important as we support the about us-with us orientations in studying deaf experiences and communities.
\end{abstract}

Keywords: language socialization; deaf culture; sign language teaching; family language policy; language in institutions of higher learning; linguistic diversity; linguistic inclusivity; visual language teaching and learning

\section{Introduction}

"Why are you here?" How can you benefit Deaf children if you aren't Deaf yourself?" Sociocultural theory (Vygotsky 1993) views learning as a form of socialization into a community of practice (Lave \& Wenger 1991). It postulates learning as inherently social and not necessarily dependent on explicit instruction (Forman \& McCormick 1995). Individuals are socialized and enculturated into communities of practice through authentic participation (Heath 1983, Lave \& Wenger 1991, Forman \& McCormick 1995) within different social settings and groups, such as the home and the family, school and peers, and the community and neighbors, to name just a few. For language acquisition, maintenance, transmission, or loss the family context is found to be the most influential (Toman 1993) and critical (Spolsky 2012). The field of family language policy (FLP) focuses on the participants - namely the family members and their individual and collective ideologies, experiences, and influences in continuous (re)negotiations of management and use of languages in the family's repertoire. However, the family milieu does not exist

\footnotetext{
${ }^{12}$ Family language policy (FLP) is a sociolinguistic field of study interested in processes that affect ideologies, management, practices, and the associated outcomes of language vitality, use, practices, fluency, etc. between the family members and within the family domain where more than one language present through one or more individuals and/or through past settlements, current linguistic environment, and/or any other experience past or present.
} 
in a vacuum and is very much affected by the external forces- such as through the presence or the absence of a supportive community. Communities of practice (Lave \& Wenger 1991) are groups of people that share a common interest or need and who often are, but do not have to be co-located, as with online communities for example. At the same time, where formal instruction is part of the learning process, such as in educational settings, teachers' beliefs and practices are found to affect the students profoundly (see Ladsen-Billings 1995, Chang 2003, Liu 2006, Menard-Warwick 2008, Osborne 1996, Siegel 2006). In the American educational context, bilingualism is by and large treated as a problem (Ruiz 1984, Lee \& Oxelson 2006) and monolingualism as the norm (Wiley 2007). Teachers who share the problem-oriented beliefs towards additional languages in a student's linguistic repertoire have students who struggle at school (Chang 2003, Liu 2006, Menard-Warwick 2008) while the opposite is true for those who view it as a resource, their students are thriving at school (Ladsen-Billings 1995, Osborne 1996, Siegel 2006). Spoken languages, as opposed to sign languages, are the norm and are a globally dominant form of communication. According to the World Health Organization (WHO) over $5 \%$ of the global population has disabling hearing loss, and in the US 1 out of 20 people is deaf or hard of hearing (Mitchell 2006). Sign languages, in most spaces and situations are minoritized in relation to the societally spoken language(s). However, in the very few situations and settings where sign and spoken languages are in contact and dominant-minority statuses are reversed, such as within the sign language classrooms, the role of teacher beliefs and practices is further amplified, particularly with hearing educators who have access to both spoken and signed languages.

In this work, our aim is to stimulate the inclusion of signed languages in FLP explorations in general. To date, the field of FLP has primarily focused on different combinations of spoken languages present within the family milieu. Here, we focus on the socialization of a hearing American Sign Language (ASL) educator into a deaf community of practice through both authentic participations as postulated by the sociocultural theory and her experiences with(in) formal education. We explore her FLP and what she has learned about the FLPs of the families that she has been active in supporting over the years, both of which include ASL. As an ASL educator, she is an important participant in the management component of the FLP of each family and individual she supports at the very least. Her involvement likely influences all aspects of FLP, including beliefs and practices as well. Thus, by examining the educator's longitudinal, experiential trajectory into the support role for these families, including her FLPs, we gain an insight into the FLP management component from a different vantage point.

\section{d/Deaf identity through languaculture and language variation}

Languaculture (Agar 1994) refers to the inseparable relationship between language and culture with meaning tying the two together as Whorf postulated, so much so that studying language is the same as studying culture. Furthermore, since languaculture "shapes consciousness, shapes ways of seeing and acting, ways of thinking and feeling...[w]hen one realizes this truth, when one's own way comes to consciousness and alternatives become possible, then the concept of culture as something that happens to a person, instead of something "those people" have, starts to make sense (Agar 1994: 71-72)." Different languacultures can be connected by comparing or organizing the differences against the similarities, according to Agar. Learning from the surprising "rich-points" or languacultural clashes, eventually lead to new and additional culture to "happen" to the individual who has put in the time and effort.

Individual identity within deaf communities is deeply rooted in their languacultures, with different definitions of belonging resting precisely on this merger of language and culture. Individuals who are physiologically deaf may or may not also be socioculturally Deaf. The upper-case D (though some scholars are beginning to abandon the $d / D$ distinctions) communicates belonging to the ethnically Deaf identity that is in opposition to the physiological deafness and hearing identity (Padden \& Markowicz 
1975) discussed below. Concurrent physiological and sociocultural deafness is communicated by the $\mathrm{d} /$ Deaf term. The most inclusive definition of deaf communities, according to LeMaster and Monaghan (2004) is Padden's (1980: 92) definition:

A deaf community is a group of people who live in a particular location, share the common goals of its members, and in various ways, work toward achieving these goals. A deaf community may include persons who are not themselves Deaf, but who actively support the goals of the community and work with Deaf people to achieve them.

Thus, being part of a deaf community, according to this, most inclusive definition does not require one to be physiologically deaf. It depends on the effort and the time invested by the individual. For example, Deaf cultures include deaf and hearing individuals who put in the effort to learn to behave in appropriate ways and to use the sign language appropriately - learning the culture and investing the time and effort for the culture to happen to them, as Agar put it. They may or may not be ethnically Deaf. To be ethnically Deaf, individuals can be hearing or physiologically deaf, and had to have either been born deaf, or born hearing to deaf parents, and whose first language is sign language (Johnson \& Erting 1989). Thus, in the most exclusive definition of deaf communities, the ethnically deaf community, birthright and first language (or languaculture) serve as determinants of belonging. Beyond this, as mentioned above, belonging depends on effort, ideologies, knowledge, and actions. Therefore, exploring beliefs and practices of those who put in the time and the effort is important in understanding their place within (deaf) communities and their impact on those communities - such as with hearing, sign language educators and their deaf communities.

\section{Language ideologies and teacher beliefs}

Language ideologies are reproduced through everyday practices (Blommaert 1999) and often reflect religious or political stances or conflicts (Gal 1998). They are the larger, overarching shared value(s) of a given group and a way of organizing responses to language(s) in social contexts (Errington 2001) that are normalized over time. Language beliefs on the other hand are more personal and individual and may or may not reflect socially dominant ideologies and discourses. Teaching practices are based on the intersection between personal beliefs and ideologies at large (Helmer 2013, Archer-Banks \& BeharHorenstein 2012, Razfar \& Rumenapp 2011), with educators' positionality between their beliefs and larger ideologies impacting student outcomes (Meador 2005). In bilingual situations of spoken languages ${ }^{13}$, problem-oriented beliefs were found to be linked to students who struggled more at school (Chang 2003, Liu 2006, Menard-Warick 2008) and resource-oriented beliefs were linked to students who were thriving at school (Ladsen-Billings 1995, Osborne 1996, Siegel 2006). Given this link for students who are hearing, it is important to explore the process and the experiences of entry into deaf communities of practice by hearing individuals whose goal is to teach future generations of those who are deaf, hard of hearing or who are prepared to put in the time and effort to support deaf communities.

\section{Family language policy and language contact}

Family is the most influential context of a person's life (Toman 1993) and a critical domain (Spolsky 2012) for language maintenance, transmission, or loss. Family language policies (FLPs) are what families do with language(s) in their lives, which languages they use, which they abandon, who decides, when, and how. Different family members can have different languages in their repertoires and different languages can be of different importance to different family members. FLP as a study can be viewed as an analysis of social interaction patterns or "... the rights and obligations of participants with respect to

\footnotetext{
${ }^{13}$ Situations in which all the languages are spoken and not signed.
} 
who can say what, when, and to whom" (Cazden 1986: 437) and in what language. It is a complex interplay of beliefs and ideologies, management approaches, and practices (Spolsky 2012) that is continuously (re)negotiated between the participants, namely family members. FLPs can be overt (Schiffman 1996) and explicit (Shohamy 2006) or they can be implicit, and both conscious and unconscious (Neustupny \& Nekvapil 2003). They are dynamic, with each participant or family member exerting influence over language choice, use, maintenance or loss within the family domain. Each individual's experiences with the outside world are brought into the (re)negotiation, whether it is conscious or not, explicit and overt or not. FLP research has focused on familial spoken language contact situations and bilingualism due to translocations, migrations, exogenous coupledom, adoptions, choice, etc. It has not, to date examined FLPs that include spoken and signed languages - in hearing families with deaf family members.

Language contact situations are complex, and they produce complicated responses (with)in individuals through bilinguality (Hamers \& Blanc 1982) and with(in) communities and societies at large. Spoken and signed language contact is perhaps even more complicated, although not as readily apparent due to the dominant position of the spoken language in communities and societies at large. Firstly, although glossing is available to sign language users, deaf communities are largely expected to use the written form of the community's spoken language. For example, American Sign Language (ASL) users who are literate use English as their written language. Thus, most deaf individuals who are literate are also bilingual. Secondly, majority of deaf children are born into hearing families with no history of deafness (Schein \& Delk 1974; Mitchell \& Karchmer 2004). Beginnings with infants are always challenging, with adjustments and time needed to settle into life. In hearing families with a deaf infant, that adjustment period is more complex. Most hearing families do not sign, and have had no exposure to sign languages, thus most deaf infants are not exposed to sign language and are instead immersed in the world of spoken language during the period of first language acquisition (LeMaster \& Monaghan 2004). With the arrival of a deaf child into the family, different beliefs, ideologies, management approaches, practices and outcomes are instigated by different FLP participants namely family members. Each family member will experience and react differently to the need for the new and signed language. Those who choose to learn the sign language will have different aptitudes and attitudes towards it, but part of their FLP management approach is to put in the effort (to learn, to communicate, etc.) and to invest the time into it. Once signing enters the linguistic repertoire of the family, contact between spoken and signed languages produces contact varieties, and different outcomes for different family members. The role of the sign-language educator and their beliefs and practices is key in supporting or hindering learner outcomes - as evidenced in studies with spoken languages discussed above. Sign language educators can have lasting effects on not only the individual's bilinguality, defined as individual's experiences with(in) the language contact situation (Hamers \& Blanc 1982), FLP and family relationships, but also on deaf communities in general.

Although spoken and signed languages of a specific region are inherently unrelated with separate grammars and historical origins (LeMaster \& Monaghan 2004; Perlmutter 2011), their relationship is intense and intertwined. Minority status of sign languages vis-à-vis spoken languages produces borrowings and pidginization within sign languages. Again, deaf individuals who are literate and/or enrolled in formal educational settings use the written form of the spoken language of their larger communities. Individuals and groups immersed in both languages have in some cases begun signing words through finger-spellings using the alphabetic letters and air-spelling rather than signing the words as entire concepts (LeMaster \& Monaghan 2004). Languages are alive and changing, and language contact is bound to produce changes. In language contact situations between the minority sign and the majority spoken languages, however, with deaf identity deeply rooted in and resting on its languaculture as discussed above, these changes can have potentially detrimental psycholinguistic, sociolinguistic, and 
sociocultural effects and outcomes on signers and deaf/Deaf communities and their languacultures at large. As researchers, turning our attention to language contact situations that include sign languages, sign language teacher socialization into a deaf community through authentic participation within a community of practice, their beliefs and their practices in formal educational settings, as well as FLP processes where language contact first occurs, is the first step in becoming an ally to deaf communities and supporting deaf languaculture(s).

In this work, we explore the trajectory of a hearing individual's socialization and entry into a deaf community of practice in the past, her beliefs and practices as an American Sign Language (ASL) instructor and early childhood deaf/hard-of-hearing educator today, and what she has learned about family language policies of families with deaf children over time. Thus, (1) we discuss participant, Molly's ${ }^{14}$ recollections and experiences of entry into the deaf community of practice and languaculture (Agar 1994) through her time at Gallaudet University. (2) We then turn to her beliefs and teaching practices as an experienced American Sign Language Instructor (ASL) and (3) lastly, we explore both, Molly's family language policies and how she understands FLPs of families with deaf children. Overall, this is an ethnographically informed logic of inquiry that aims to merge several related but often separate fields of deaf studies, teacher beliefs, and FLP in order to gain better understandings of the socialization processes into and within deaf languaculture(s) (Agar 1994). We end with a brief discussion on the position of sign languages in today's mainstream education and the importance of inclusion of visual languages in all discussions about language and linguistic diversity.

\section{The study \\ Method}

The logic of inquiry (Green, Dixon \& Zaharlick 2005) of this study is ethnographic in nature and relies on the telling case analysis (Mitchell 1984). Specifically, we apply the ethnographic logic of inquiry in exploring the discursively (de/re)constructed experiences our participant, the telling case (Mitchell 1984), communicates with us within and across times and ways. This allows us to trace her development of knowledge that guides her entry into a community of practice, eventually serving as a lens through which she views and experiences family language policies. Mitchell explains: "[e]thnographic reportage tends to be general in form: the analyst makes statements about the overall pattern of behavior or belief derived from extensive observation" (p. 237) while the telling case is that "...in which the particular circumstances surrounding a case...serve to make previously obscure theoretical relationships suddenly apparent. It follows from this that the particularity of the circumstances surrounding any case or situation (or set of situations) must always be located within some wider setting or context. Any general statement which links theoretically relevant events or phenomena must always assume that 'other things are equal' Case studies allow analysts to show how general regularities exist precisely when specific contextual circumstances are taken account of. When it is difficult to do this, then it is likely that the theoretical formulations of the regularities underlying the regularities needs some revisions (Mitchell 1984: 239). "Furthermore, this study is rooted in the sociocultural theory (Vygotsky 1993) which views learning as a form of socialization into a community of practice (Lave \& Wenger 1991) through authentic participation (Heath 1983, Lave \& Wenger 1991, Forman \& McCormick 1995). Thus, we place particular importance on the authentic and longitudinal experiences that contributed to the socialization of our participant into her d/Deaf community of practice at first, and later influenced her positionality as an educator involved in supporting individuals and families into a community of practice whose FLPs include ASL.

${ }^{14}$ The name of the participant was changed in order to ensure her anonymity. 
We learned about Molly's experiences through many informal, in-person conversations, over a period of 4 years, as well as formal interviews, questionnaires, and e-mail exchanges more recently. Our understanding of her experiences reported here is rooted not only in her responses to our questions, but rather in our emic engagement with the topic, with Molly, over an extended period of time. We had no predetermined checklists and questions while engaging with Molly, and we later triangulated, clarified and verified her positions on our observations and conversations through questionnaires and email exchanges. Our study is ethnographic in nature as Green, Dixon, and Zeharlick (2005: 148) propose it to be: "[An] observer who enters with a predefined checklist, predefined questions or hypotheses, or an observation scheme that defines, in an a priori manner, all behaviors or events that will be recorded is not engaging in ethnography, regardless of the length of observation or the reliability of the observation system. Further, if the observer does not draw on theories of culture to guide the choices of what is relevant to observe and record or overlays his or her personal interpretation of the activity observed, they are not engaging in an ethnographic approach from an anthropological point of view." In addition to the emic perspective guiding this ethnographic study, we remained aware of our positionality ${ }^{15}$ and our receptiveness to Molly's lived experiences as rooted in our very own engagement and interest with the study of language learning and teaching, language contact situations, bilingualism, and family language policy. The topics presented here emerged through a combination and an interaction of what mattered to Molly primarily with our drawing on theories of languaculture (Agar 1994), communities of practice (Lave \& Wenger 1991); teacher beliefs and the study of FLP to guide our observations, questions we posed, and what we zoomed in on. All the conversations, e-mails, and discussions were conducted in English.

\section{Molly}

Molly is one of three ASL instructors at her institution and the only instructor who is also hearing. Although all three instructors were invited to participate in the larger, ASL FLP study, Molly's journey into the $d$ /Deaf community of practice through authentic participation was of particular interest for the current work.

Molly is a mother to two boys, a wife, a daughter, and an experienced higher education instructor of the ASL and an educator ${ }^{16}$ of deaf and hard-of-hearing children in her county through daycares and home visits. Her qualifications include advanced degrees from Gallaudet University and 13 years of experience in the field. In her community college classes she teaches hard of hearing and hearing students, with hearing students making up most of her student population over the years. According to Molly, the fact that most of her adult students are hearing is not surprising as majority of deaf individuals do not formally study ASL (discussed below). Although her professional plan did not include teaching college level ASL, she has been a college ASL instructor for 13 years: "I actually never anticipated this being my field. My goal was to teach families who have DHH (deaf and hard-of-hearing) children how to sign. Teaching ASL in the college level fell into my lap." Molly is one of three instructors and the only hearing instructor in her department. Her interest into ASL and deaf cultures was not fueled by having deaf family members or friends, instead it was sparked by an inspiring student teacher when she was in $6^{\text {th }}$ grade: "I did not have any D/deaf friends or family members in my childhood. My first exposure to ASL was a student teacher I had in 6th grade who taught us a song in ASL for a winter

\footnotetext{
${ }^{15}$ Positionality: we recognize that we are outsiders, though allies of deaf communities and individuals, and insiders of the community of educators focusing on language and social justice that Molly is engaged in. We firmly believe in the about us - with us sentiment. The focus of this work is on the hearing educator's journey into the deaf community of practice and not about deaf individuals, communities, or cultures.

${ }^{16}$ Molly's title is Deaf and Hard-of-Hearing Infant/Toddler Specialist. She is employed through her county's education office.
} 
concert. I loved it and apparently was pretty good at it because she had me lead the group out in front. I didn't really have any further exposure to ASL until college when I wanted to take the course." At university, Molly took ASL classes for a year and continued on to earn her Associate of Arts degree in ASL interpreting at a local community college. Molly was interested in attending Gallaudet as it was one of the only two universities that offered an advanced degree in her area and population of interest. Furthermore, her desire was to support families with deaf children through ASL, rather than a spoken language, an option that only Gallaudet offered. Molly explains: "I chose Gallaudet because there were only two universities at the time that offered a Master's degree in the very specific field of Early Childhood Deaf/Hard-of-Hearing (birth-3). I thought being on an all-Deaf campus would really be the best way for me to get the education I needed to really be effective in this field. Additionally, I chose Gallaudet because they did focus on using sign language as one of the main options for families who had a child with a hearing loss. I believe the other option was a university that focused more on oral education for students who are Deaf. "Molly enjoys teaching adults, but her passion has always been engagement with younger children and their families.

\section{Entry into deaf languaculture and community of practice}

Although Molly's entry into Deaf languaculture and community of practice took place within the formal educational context of Gallaudet, which included explicit instruction, we were particularly interested in her experiences outside of the classroom and within her community of peers. Molly explains:

In my small cohort of students (there were 5 of us) there was definitely judging of the hearing students by the Deaf students. Hearing students had to prove themselves to the Deaf community. There were questions of "Why are you here?" How can you benefit Deaf children if you aren't Deaf yourself?" There was also a feeling that the hearing students at the school were there to "help" the Deaf children (as if we had pity on them and felt we needed to "save" them). Deaf students did not like the thought of hearing students being helpers. I really had to prove myself to the Deaf community on campus that I was a guest on their campus and wanted to learn about their language and their culture. Any hearing students who thought of themselves as "better than" were not looked upon highly. Also, students on campus who did not use ASL were also not looked upon well. Lastly, if you were on campus and talking without signing, you were really looked down upon. That was like telling a secret right in front of someone's face. The expectation was that everyone had equal access to language, and that was a visual language (sign).

Here we asked Molly to elaborate. We mentioned that on a hearing campus, asking foreign language speakers to refrain from using their language would be considered problematic and discriminatory, and asked her to elaborate on how and why the two acts would be different.

I do think that speaking on the Deaf campus is rude and would be offensive to students there. I think that it is different than another language being spoken on a US hearing/mainstream campus. The reason is twofold: 1 . There is only one Deaf university in the world. A hearing student has thousands of options in choosing their higher level of education. A Deaf student who uses ASL as their primary language only has one option. I believe that this university for the Deaf is special and unique in that it is the only place in the world that ASL is the primary language of the majority. Everywhere else in the country a Deaf person is in the minority. At this school they can be free to interact using their native language and not having to struggle to communicate through amplification or reading lips or an interpreter. I felt privileged to be accepted into the university as a hearing student. For undergrad students the population of hearing students is something like less than $1 \%$. For graduate school it was closer to $50 / 50$. I felt like a guest on that campus, and I felt I should be respectful of its language and culture. It was a 
privilege for me to be there. However, I know that other hearing students did not feel the same way. Many hearing students didn't care or even try to sign while they were talking, and it didn't bother them in the least. 2 . The second part of my reason for believing it is different is because if a person is speaking another language on a U.S. campus, I still have the ability to have access to that language. I may not understand it, but if I chose to, I could learn that language. A Deaf person may not have access to spoken language, due to not being able to hear it. They don't have the same opportunity that I would have to learn a foreign spoken language. With all that said, I still sometimes feel offended when I hear people using a foreign language in front of me, because I feel like they are excluding me from the conversation on purpose. I believe that is rude. However, if a group of students are talking amongst themselves in another language on campus and I just happen to be walking past them, that does not bother me.

Molly's divergent perceptions toward foreign language use in social settings capture the complicated dynamic of bilingualism that includes languages with different modalities. The associated languaculture, status and accessibility are inseparable from the language itself.

\section{The classroom context: teacher beliefs and practices}

During her studies Molly felt that there was favoritism: "In my program I felt that Deaf instructors favored Deaf students. I would venture to say that hearing instructors favored hearing students too (but I don't know that for sure)." Molly is a hearing instructor of ASL and has been for the past 13 years. As most of her students are hearing Molly thought that they felt more comfortable with a hearing teacher, "even though I do not allow them to speak to me for any reason. I think they are more intimidated by a Deaf professor. However, once they get to know the Deaf instructors, they truly love them." At the same time, she still perceives the deaf community as not entirely accepting of her position as a hearing educator teaching ASL, her initial, educational experiences continuing, though not in her immediate work environment(s): "I would say that Deaf ASL instructors (not in San Miguel) but in other areas frown upon hearing teachers teaching ASL. It is not my first language, and they believe (and I agree) that a Deaf teacher can often be a better teacher of their native language". Considering the native/non-native spoken language teacher debate and the research on the topic within the academic community, such as those pertaining to English language educators (Inbar-Lourie 1999, Inbar-Lourie 2005, Nayar 2002) and their associated access to resources and capital (Bourdieu 1991), we were interested in her perceptions and experiences as a non-native ASL educator. She shared with us her positionality, which included deep awareness of her lack of authentic experience with ASL due to her access to spoken language and hearing status. At the same time, she is aware that her training may have prepared her, perhaps even better in some cases and for some students to teach the languages she herself learned as a second language:

I think a Deaf teacher who is a native ASL user has more to offer both Deaf and hearing students learning ASL. The language comes naturally to them. They use and have used it every day for most of their lives. But more than just the language aspect is the cultural component. Deaf culture and Deaf history play a huge role in the Deaf community and in ASL. I cannot pass on personal experiences with Deaf culture. I can share my knowledge that I have observed or read in books, but I have not experienced it first-hand. Only a person who has lived that can share that. The only thing that I do feel I have that some native users don't have is formal education in the linguistics of ASL. I have taken over 20 ASL language classes and classes in the study of linguistic features of ASL. Most native Deaf ASL users have not taken any ASL classes or any linguistics classes about ASL. It is crazy to me that as a native English speaker I have taken 
English classes from kindergarten through university level and native ASL user has likely never taken an ASL class in their life.

Regardless, Molly works hard on safeguarding the practices of her deaf colleagues and those without access to spoken language through her own teaching philosophy and practices:

My philosophy is the same as the other professors at my college (the other two are Deaf). We strongly adhere to a voice-off policy. This means that students may not talk in the classroom at all (to each other or to the professor). I am often asked if they can speak to me during office hours or at break and the answer is always "no". The expectation is that they have the same experience as the student who has a Deaf professor. I work really hard at not having my philosophy be influenced by my hearing status.

Although she internalizes her otherness from deaf, native ASL instructors due to her hearing status as discussed in her positionality above, some of her sentiments echo desires for recognition:

I wish they realized that although ASL is not my first language, I studied very hard to become proficient in the language. I took several courses that educated me on how to teach the language. This is something that a lot of native users may have intrinsically but were not taught specifically. I think that I can really relate to my ASL students in a way because I was once like them (learning ASL for the first time).

We were interested in whether Molly's voice-off teaching philosophy was truly hers, or whether her entry into the deaf community and culture as a hearing person imposed it. Through our discussions we learned that it is the combination of her experiences within the community as well as her experiences as a student of foreign languages, ASL and Spanish. She explained that she had first learned from a deaf instructor, and that although her later experiences of learning with hearing instructors left her less frustrated, she felt that she did not have the same kind of quality of experience as with her deaf instructor. She had learned more. She reflected on her experiences with learning Spanish: "All of my teachers used both English and Spanish in the class and I never really felt like I learned the language. I truly believe in a full immersion kind of experience for second-language learners. So, I think my philosophy would be the same had I not undergone the experience at Gallaudet of proving myself. I truly believe that is the best way to learn another language." For Molly, her beliefs rooted in personal learning experiences, and internalized ideologies of the deaf community of practice she had joined are the bases of her teaching philosophy and practices.

\section{Defining bilingualism}

We argued elsewhere (Hirsch \& Kayam 2020) that any study of bilingualism, bilinguality, or the bilingual individual should begin with the question that clarifies how the participant defines bilingualism itself. This practice will ensure that the researchers are clear on what they are studying, contextualizing the responses and discussions with the participant(s) within the parameters tailored for and by the participants themselves. Thus, we wanted to know how Molly - a hearing instructor of ASL -defines bilingualism. Through her answer we see that once again, both, her experiences and education guide her understanding of it:

Being bilingual is the ability to use two languages fluently. Both languages do not need to be in the same form. One could be spoken and the other signed. Or one could be signed and the other written/read. Or both could signed or both could be spoken. For example, a Deaf person who is bilingual doesn't necessarily mean they speak English and sign ASL. It could be they sign ASL and can read/write English. I would consider that bilingual.

Molly explained that most deaf people she knows are bilingual in English and ASL. She explains: "Both (English and ASL) are very different languages with very different grammatical structures." She 
continued by stating that she didn't know too many Deaf people who are trilingual, but she proceeded to share with us the experiences of one Trilingual Deaf person she did meet:

One of my colleagues is trilingual. English, Spanish, and ASL. His first language was Spanish, and he learned English and ASL at the same time. I remember that he told me that his English teachers expected not be able to learn English because he was Deaf. They prejudged his abilities for English based on his hearing. They were shocked when he was exceeding his hearing peers' mastery of the English language.

As the written form of sign languages is not represented in societies and education systems at large, including the ASL glossing, many deaf individuals develop literacy skills in the spoken language of their surroundings. Thus, in the United States ASL signers use written English. Molly explains:

ASL signers use English as their written language. There is not a written equivalent in ASL. However, there is GLOSSING that is used for linguistic studies and for teaching the language. It does not have a written form that can be used for reading and writing. It is used only for teaching and studying and documenting the language.

She considers herself as bilingual because of her command of ASL, and interestingly not based on her knowledge or learning of Spanish. Molly's definitions of bilingualism seem to include a certain and high level of fluency she has not reached in Spanish.

\section{Family language policy of ethnically deaf: deaf child - hearing families}

Communication between parents and children is of utmost importance in linguistic and social development of children. However, with over $90 \%$ of deaf children born to hearing parents who are not proficient in effectively communicating with their deaf child (Vaccari \& Marschark 1997), the role of community educators such as Molly, is of paramount importance in bridging that gap and providing a successful path to a community of practice and communication within the family.

As a community of practice member who works closely with families of deaf and hard-of-hearing infants and toddlers, entering their homes and daycares during the period of adjustment to parenthood, early childhood education, and most importantly a new language in an entirely new modality, we were interested in how Molly experienced and what she had learned regarding the FLPs of those families.

In my experience in this small town, most family members do not learn ASL. Most want their children to learn to speak and do not take the time to learn ASL. Of those that do learn ASL, usually only the mother learns. The extended family almost never learns (at least not in my experience). I did have one family that wanted all of their friends, neighbors, and extended family to learn so they hired me to teach them all in a night class. It was great!

Most of my Deaf friends either had family who didn't sign at all or just the mom signed. Most kids were left out of family conversations at the dinner table, or the mom acted as an interpreter. Most of my Deaf friends said their family could communicate with them basics, such as "I love you," and other simple phrases. Deaf people are often left out of conversations in their own families. This is true of hearing families with a Deaf child. However, a Deaf family with a Deaf child is a totally different story. The whole family communicates in ASL and therefore no one is left out. In my current work with Deaf children, it is rare that a family member learns ASL. Again, if someone learns it is the mom. Most of the time the child is expected to learn to speak English and use their technology or read lips to communicate with their family.

What she shares is jarring, though not unexpected. In her experience, mothers are by and large the language socializers, supporters, interpreters, and advocates of/for their children. They put in the invisible work (Okita 2002) of supporting and nurturing bilingualism. 


\section{Molly's FLP}

As someone so immersed in deaf languaculture, with so many experiences rooted in her time spent learning within and from deaf communities, teaching ASL, and allowing deaf culture to happen to her, we were interested in whether ASL entered her own FLP.

Before I had children I had hoped my children would be fluent in ASL. I used ASL with them when they were babies and they picked it up quickly and used it way before they learned to speak. My first son's first sign was at 10 months and my second son's first sign was at 6 months. They each had over 50 signs by the time they were 18-months old. They developed spoken language and I started to drop using the signs with them. As they have gotten older we have picked up signing again here and there but I don't use it with them enough. I wish they were fluent and I wish I was more consistent with them. I hope one day they will have an interest in it again.

Molly's FLP initially included ASL, with time however, her (and her husband's) FLP practices and management allowed for English to take over. As a parent of two hearing children, their developing abilities in English led to a renegotiation of their FLP. Whether conscious or subconscious, explicit or implicit, the new FLP did not include ASL practices. Although Molly clearly values ASL, the routine of daily life and the convenience of communication with her children in their developing spoken language prevailed. This is often the case even with heritage languages in host language settings, where even those families who speak a common heritage language consciously or not, explicitly or not, allow for the host language to take over in their practices - or communications - with their children (Fishman 2006).

\section{Discussion and conclusions}

Molly is an active member and an ally of the deaf community of practice and languaculture. We refer to Molly as an ally as she is committed to upholding and supporting sociolinguistic justice of linguistically marginalized individuals and communities through her actions and positionality. Sociolinguistic justice is defined as "self-determination for linguistically subordinated individuals and groups in sociopolitical struggles over language...most immediately rooted in practice rather than policy (Bucholtz et al. 2014: 145)." Thus, although she is not physiologically deaf, ethnically Deaf (Padden \& Markowicz 1975), or socioculturally $d$ /Deaf, she has undergone the socialization process through authentic participation at Gallaudet University and beyond and continues to support the linguistically subordinated individuals and groups through her practices, such as for example - her "voice off policy" at all times in the context of her ASL instruction. Research on the efficacy of the voice off approach are inconclusive with some studies showing increased efficacy for the voice off approach (Rosen, DeLouise, Boyle, \& Daley 2014), while others showing no significant differences between the voice on and the voice off approaches (Traxler \& Nakatsukasa 2018). Molly's stance on the voice off policy is informed by her experiential trajectory into the $d /$ Deaf community of practice and continued awareness of her hearing status within it. She has and continues to put in the time and effort in supporting the community. Through her studies, fluency in ASL, authentic participation, as well as involvement with the Deaf community over the years Deaf culture "happened to her" as Agar (1994) puts it. She became part of the community by "actively support[ing] the goals of the community and work[ing] with Deaf people to achieve them (Padden 1980: 92)." At the same time, Molly treads carefully when alluding to belonging with(in) the deaf community, due to her hearing status and her privilege of access to the spoken language. Although clearly extremely educated and knowledgeable on the topic of deaf culture (See Appendix A for her definitions and explanations), her definitions are more rigid than those of academics studying deaf/Deaf culture (discussed above). This stringency coupled with her communicated uncertainty about her ability 
to adequately teach courses on Deaf culture because her knowledge is not rooted in her very own lived experiences as it is for Deaf instructors, show her struggle with her membership. The, what seems to be constant and concurrent struggle between her confidence in her skills and qualifications and her questioning of those abilities due to her non-native and hearing status seems to be the perfect combination in creating an ally to and a member of a community who is truly supportive of the languaculture.

Although Molly teaches and supports deaf and hard-of-hearing infants and toddlers and their families, much of her career has also been devoted to teaching hearing and heard of hearing adult students, with hearing adult students making up a large majority of the students she has taught over the past 13 years. This and her accounts of the demographics of her cohorts at Gallaudet point to two observations that need to be explored further: 1) community colleges attract hearing students to their ASL classes, yet at Gallaudet only $1 \%$ of the students at an undergraduate level are hearing and 2) at the only deaf university in the world, the majority of undergraduates are deaf, while the graduate ASL studies are populated by both hearing and deaf students approximately equally. These observations lead to questions of access - an important point Molly has brought up in the context of differences in physiological access to languages between deaf and hearing individuals, but here it points to institutional access as well. Is it indeed true that most ASL students nationally, at community colleges, are hearing and not deaf? If so, why are deaf students not enrolling in arguably more accessible option of community college - financially and geographically? What can be done to increase deaf enrollment in ASL studies outside of Gallaudet? At the same time, space was offered to hearing individuals at Gallaudet who, according to the perceptions of their peer, had questionable degree of respect for their surroundings - as communicated through their use of spoken language only while on campus where majority of the population relies on visual communication. Fifty per cent of the graduate students according to Molly were hearing at Gallaudet. Why don't more deaf undergraduate students continue onto graduate studies in ASL? How are deaf individuals supported in public institutions of higher learning? Evidence shows that supporting heritage language and culture has lasting positive effects in several aspects - healthy identity development and academic performance among children, for example (Lee \& Suarez 2009). Although this evidence is based on work done with individuals with heritage languages that are spoken, it can be inferred that such responses would be observed among the population of individuals and groups who use visual languages as well. Strong social and cultural embedding were found to be of higher relevance in children's perceived quality of life than their hearing status (Hintermair 2011). Community access matters. Families with deaf children who have access to deaf communities of practice support their deaf child more successfully and feel more positively regarding their parenting overall. Families with deaf children whose parents "...frequently meet with other parents show evidence of a warm, accepting, trusting relationship with their child. Parents who have many contacts with hearing-impaired adults show evidence of a strong sense of competence in regard to their child's upbringing (Hintermair 2000). Without guidance by educators such as Molly, for most hearing parents with deaf or hard-of-hearing children, the path to the community, as well as FLP that includes ASL is difficult. Thus, the experiences of educators who are in key roles of supporting and guiding deaf and hard-of-hearing children and their parent's trajectories into social and cultural embeddings of deaf communities are important areas of investigations theoretically and practically.

The minority status of sign languages is unmistakable. Sign languages are often overlooked entirely, both by policy makers and educators. In our previous work with academic mothers, a category Molly falls into, we asked 46 highly educated women who work or have worked in an academic institution of higher learning, many as teaching professors and/or instructors to define bilingualism (Hirsch \& Kayam 2020). All the women focused on spoken languages, most on oral skills, with only a few of the women incorporating literacy into their definitions. When asked to define bilingualism, not surprisingly, Molly 
actively includes sign languages in her definition (see above). When asked about her FLP, she discusses teaching her children ASL when they were younger and mentions having no preference over whether they learn a spoken or a signed language later in life. Though Spanish is Molly's children's heritage language (through their father) and arguably a language that is easier to capitalize on with its more central position in the global economy (de Swaan 2013), to Molly, ASL is as important and as valuable as Spanish. A beginning to making mainstream public institutions of higher learning more attractive and welcoming to sign language users could begin by including sign languages in discussions about language - in academic circles through research but also in teacher education programs. In addition to the necessary discussions on spoken languacultural diversity, the value of additional languages and cultures and how heritage, communal, familial, languacultural knowledge or what Moll, Amanti, Neff, and Gonzalez (2005) referred to as the funds of knowledge can be drawn on in order to promote success amongst students, sign languages should be included in all discourses about language(s) and linguistic diversity. Normalizing the visual language presence among the spoken languages may be the beginning of normalizing the presence of sign language users on mainstream campuses.

Molly's path to membership in the only community and space dedicated to deaf and hard- of-hearing higher education students was initially met with mistrust. This is not surprising, given the experiences of those who are physiologically deaf with even those who are closest to them. The majority of deaf children are born to hearing parents (Schein \& Delk 1974, Mitchell \& Karchmer 2004), and in our discussions with Molly on FLPs of families with deaf children we confirm that most hearing parents and family members do not learn to sign (see Rawlings 1973, Harvey 1984, Mayers \& Bartee 1992) to accommodate and open the lines of communication with their deaf child or family member - mothers most often being the exceptions, serving as the only links and language brokers (Orellana 2009) between the deaf child and the rest of the family. This is in line with research on spoken language socialization within the family: language socialization falls on the mother (Okita 2006) during the "second shift" at home (Hochschild \& Machung 2012), even in dual-career couples. Hence, and not surprisingly, outsiders who are interested and willing to learn to sign and display the desire to enter the community are met with suspicion. This is compounded by the behavior of some hearing "guests," as Molly referred to the hearing students at Gallaudet, in one of very few spaces where linguistic dominance is reversed. Here too, we would argue that normalizing the presence of sign languages in all discussions of linguistic diversity would empower those who use visual languages and possibly encourage spoken language users to be more sensitive and aware of their communication patterns.

Many physiologically deaf individuals do not formally study sign language, according to Molly therefore those who do, and those who attended Gallaudet University - may have viewed Molly and other hearing students as a threat to their future employment. This, too, is in line with previous research on spoken, native/non-native language teacher relationships, where native speakers are found to be reluctant to share the wealth or the capital (Bourdieu 1991) with the non-native-language teachers (Inbar-Lourie 1999). Non-native speakers, in this case the hearing teachers, are aware of the d/Deaf instructor's ability to relate to physiologically deaf individuals and impart Deaf culture as rooted in their personal and lived experiences in a way that hearing teachers cannot. Native, or in this case Deaf teachers are aware of the non-native teachers' advantage in terms of familiarity with the local dominant language and culture [of the spoken language], their access to spoken language and ability of hearing instructors to support literacy and bilingual development in societally dominant spoken language in a way that deaf instructors have no access to. In addition, hearing teacher's familiarity with the process of learning the sign language (Seidlhofer \& Widdowson 1998) may be viewed as a benefit to non-deaf individuals interested in learning the sign language- regardless of the teacher's teaching philosophy which may, as in Molly's case include the "Voice off "policy. But even with all the advantages available to hearing teachers of sign languages through their physiological access to both societally dominant 
spoken language and the sign language - Molly's comment about her qualifications echoes those of the non-native spoken language teachers - and their struggle with their place as teachers of someone else's native language. Should they do it? Do multiple courses in instruction and linguistics matter more or at least as much as lived experience?

According to Molly's recollections some of her hearing peers at Gallaudet did not see the importance of upholding and honoring the cultural and communicative norms of the deaf-majority campus. It makes us wonder how they approach their work, their time with the families with deaf children, and their deaf community of practice and if they indeed remain involved in deaf cultures through their professional and personal activities. It is likely that they are not part of the community as outlined by even the most inclusive of definitions, regardless of the time they put into it. Perhaps the key here is not only the time but also the type and quality of effort invested. Individuals who do not foreground their privilege and do not examine their ableist stances are likely to bring beliefs and attitudes into their classrooms that may impact deaf individuals and families adversely. It is important to continue to explore sign language socialization in order to better understand the processes that support positive cultural preservation and transmission amongst deaf, Deaf, $d$ /Deaf and hearing individuals who are part of their deaf communities. A good start to that would be the inclusion of signed, visual languages in all discussions of language-related experiences- from the most influential domain of the family, as we have initiated here to the education domain and beyond. Although findings of this study are not generalizable, it makes visible an area of study that has largely been unexplored. The inclusion of sign languages and experiences of families with differently abled individuals in the study of FLP may prove to deepen our understanding of the interactions between individual ideologies, family internal experiences, management approaches, and practices within the family domain, within the communities of practice, and beyond in a way that is distinct and instrumental from situations where two or more spoken languages are involved.

\section{References:}

Agar, M. (1994). Language Shock. Understanding the Culture of Conversation. NY: William Morrow \& Co.

Archer-Banks, D. A., Behar-Horenstein, L. S. (2012). Ogbu Revisited: Unpacking High-Achieving African American Girls' High School Experiences, Urban Education, 47(1), 198-223.

Blommaert, J. (1999). The debate is open, in: J. Blommaert (ed.), Language Ideological Debates, (pp. 138). Berlin: Mouton de Gruyter.

Bourdieu, P. (1991). Language and Symbolic Power. Cambridge, MA: Harvard University Press.

Bucholtz, M., Lopez, A., Mojarro, A., Skapoulli, E., VanderStouwe, C., Warner-Garcia, S. (2014). Sociolinguistic justice in the schools: Student researchers as linguistic experts. Language and Linguistics Compass, 8(4), 144-157.

Cazden, C. B. (1986). Classroom discourse, in: M. C. Wittrock (ed.) Handbook of research on teaching. 3rd ed. (pp. 432-463). New York: Macmillan.

Chang, L. (2003). Variable Effects of Children's Aggression, Social Withdrawal, and Prosocial Leadership as Functions of Teacher Beliefs and Behaviors. Child Development, 74(2), 535-548.

De Swaan, A. (2013). Words of the World: The Global Language System. New York, NY: John Wiley \& Sons.

Errington, E. P. (2001). The Influence of Teacher Beliefs on Flexible Learning Innovation in Traditional University Settings. London: Kogan Page.

Fishman, J. A. (2006). Language loyalty, language planning, and language revitalization: Recent writings and reflections from Joshua A. Fishman, 59, Multilingual Matters.

Forman, E. A. \& McCormick, D. E. (1995). Discourse Analysis: A Sociocultural Perspective. Remedial and Special Education, 16(3), 150-158. 
Gal, S. (1998). Multiplicity and Contention among Language Ideologies: A Commentary. Language Ideologies: Practice and Theory, 317-331.

Green, J. L., Dixon, C. N., Zaharlick, A. (2005). Ethnography as a Logic of Inquiry. Methods of Research on Teaching the English Language Arts, 155-204. Routledge.

Hamers J.F., Blanc M. (1982). Towards a social-psychological model of bilingual development. Journal of Language and Social Psychology, 1(1), 29-49.

Harvey, M. A. (1984). Family therapy with deaf persons: The systemic utilization of aninterpreter. Family Process, 23(2), 205-213.

Heath, S. B. (1983). Ways with Words: Language, Life and Work in Communities and Classrooms. Cambridge, UK: Cambridge University Press.

Helmer, K. A. (2013). A Twice-told Tale: Voices of Resistance in a Borderlands Spanish Heritage Language Class. Anthropology \& Education Quarterly, 44(3), 269-285.

Hintermair M. (2000). Hearing impairment, social networks, and coping: The need for families with hearing impaired children to relate to other parents and to hearing-impaired adults. American annals of the Deaf, 145(1), 41-53.

Hintermair, M. (2011) Health-related quality of life and classroom participation of deaf and hard-ofhearing students in general schools. Journal of deaf studies and deaf education, 16(2), 254-271.

Hirsch, T., Kayam, O. (2020). Academic mothers' definitions of bilingualism, bilinguality, and family language policies. Psychology of Language and Communication, 24(1), 22-43.

Hochschild, A., Machung, A. (2012). The Second Shift: Working Families and the Revolution at Home. London: Penguin.

Inbar-Lourie, O. (1999). The Native Speaker Construct: Investigation by Perceptions. Unpublished doctoral

dissertation. Tel-Aviv University, Tel-Aviv, Israel.

Inbar-Lourie, O. (2005). Mind the gap: Self and perceived native speaker identities of EFL teachers, in: $\mathrm{E}$. Llurda (ed.), Non-native language teachers: Perceptions, challenges, and contributions to the profession (pp. 265-281). Boston, MA: Springer.

Johnson, R.E., Erting, C. (1989). Ethnicity and socialization in a classroom for deaf children, in: C. Lucas (ed.). The sociolinguistics of the Deaf community (pp. 41-83). New York, NY: Academic Press.

Ladson-Billings, G. (1995). Toward a Theory of Culturally Relevant Pedagogy. American Educational Research Journal, 32(3), 465-491.

Lave, J., Wenger, E. (1991). Situated Learning: Legitimate Peripheral Participation. London: Cambridge University Press.

Lee J.S., Oxelson E. (2006). It's not my job: K-12 teacher attitudes toward students' heritage language maintenance. Bilingual Research Journal, 30(2), 453-477.

Lee, J. S., Suarez, D. (2009). A synthesis of the roles of heritage languages in the lives of children of immigrants: What educators need to know. The education of language minority immigrants in the United States, 136-171.

LeMaster, B., Monaghan., L. (2004). Variation in Sign Language, in: A. Duranti (ed.), Companion to Linguistic Anthropology. (pp. 141-165). Malden, MA: Blackwell

Liu, S. H. (2011). Factors related to pedagogical beliefs of teachers and technology integration. Computers \& Education, 56(4), 1012-1022.

Meyers, J., Bartee, J. (1992). Improvements in the Signing Skills of Hearing Parents of Deaf Children. American Annals of the Deaf, 137(3), 257-260.

Meador, E. (2005). The Making of Marginality. Anthropology \& Education Quarterly, 36(2), 149-164. 
Menard-Warwick, J. (2008). The Cultural and Intercultural Identities of Transnational English Teachers: Two Case Studies from the Americas. TESOL Quarterly: A Journal for Teachers of English to Speakers of Other Languages and of Standard English as a Second Dialect, 42(4), 617-640.

Mitchell, C. J. (1984) Case Studies, in: R. F. Ellen (ed.) Ethnographic Research: A Guide to General Conduct (pp. 41-83). London: Academic Press.

Mitchell, R. E. (2005). How many deaf people are there in the United States? Estimates from the Survey of Income and Program Participation. Journal of deaf studies and deaf education, 11(1), 112-119.

Mitchell, R., Karchmer, M. (2004). Chasing the Mythical Ten Percent: Parental Hearing Status of Deaf and Hard of Hearing Students in the United States. Sign Language Studies, 4(2), 138-163.

Moll, L., Amanti, C., Neff, D., Gonzalez, N. (2005). Funds of knowledge for teaching: Using a qualitative approach to connect homes and classrooms. Funds of knowledge: Theorizing practices in households, communities, and classrooms, 71-87.

Nayar, B. (2002). Ideological Binarism in the Identities of Native and Non-native English Speakers. Pragmatics and Beyond New Series, 463-480.

Neustupný, J. V., Nekvapil, J. (2003). Language Management in the Czech Republic, Abingdon-onThames. UK: Taylor \& Francis, 181-366.

Okita, T. (2002). Invisible work: Bilingualism, language choice and childrearing in Intermarried families (Vol. 12). John Benjamins Publishing.

Okita, T. (2002). Invisible work: Bilingualism, language choice and childrearing in Intermarried families. IMPACT: Studies in Language and Society. Philadelphia: John Benjamins Publishing.

Orellana, M. F. (2009). Translating childhoods: Immigrant youth, language, and culture. Rutgers University Press.

Osborne, J. F. (1996). Beyond Constructivism. Science Education, 80(1), 53-82.

Padden, C. (1980). The Deaf Community and the Culture of Deaf People Sign Language and the Deaf Community, 89-103.

Padden, C., Markowicz, H. (1975). Culture Conflicts Between Hearing and Deaf Communities, in: F. B.

Crammatte and A. B. Crammatte (Eds.), Proceedings of the Seventh World Congress of the World Federation of the Deaf (pp. 407-411). Silver Spring, MD: National Association of the Deaf.

Perlmutter, D. (1992). Sonority and syllable structure in American Sign Language. Linguistic Inquiry, 23 : 407-442.

Rawlings, B. (1973). Characteristics of Hearing Impaired Students by Hearing Status. United States: 197071.

Razfar, A., Rumenapp, J. C. (2011). Developmental Context(s): Mediating Learning through Language Ideologies. Human Development, 54(4), 241-269.

Rosen, R. S., DeLouise, M., Boyle, A. T., Daley, K. (2014). Native language, target language, and the teaching and learning of American sign language vocabulary, in: D. McKee, R. S. Rosen, R. McKee (Eds.), Teaching and learning signed languages: International perspectives and practices (pp. 145-174). Basingstoke: Palgrave Macmillan.

Ruiz, R. (1984). Orientations in Language Planning. NABE Journal, 8(2), 15-34.

Schein, J. D., Delk, M. T., Jr. (1974). The deaf population of the United States. Silver Spring, MD: National Association of the Deaf.

Schiffman, H. F. (1996). Linguistic Culture and Language Policy. New York, NY: Routledge.

Seidlhofer, B., Widdowson, H. G. (1998). Applied Linguistics, Pragmatics, and Language Pedagogy, in: Beaugrande, R., Grosman, M. and Seidelhofer, B. (eds.), Language Policy and Language Education in Emerging Nations. (pp. 3-14). Stamford, CT: Ablex.

Shohamy, E. (2006). Language Policy: Hidden Agendas and New Approaches. London: Routledge. 
Siegel, J. (2006). Language Ideologies and the Education of Speakers of Marginalized Language Varieties: Adopting a Critical Awareness Approach. Linguistics and Education, 17(2), 157-174.

Spolsky, B. (2012). Family Language Policy - The Critical Domain. Journal of Multilingual and Multicultural Development, 33(1), 3-11.

Toman, W. (1993). Family Constellation: Its Effects on Personality and Social Behavior. New York, NY: Springer Publishing Company.

Traxler, R. E., Nakatsukasa, K. (2018). The effectiveness of voice-on and voice-off instruction on ASL vocabulary acquisition. Language Teaching Research, 24: 1-14.

Vaccari, C., Marschark, M. (1997). Communication between parents and deaf children: Implications for social emotional development. Journal of Child Psychology and Psychiatry, 38(7), 793-801.

Vygotsky, L. S. (1993). Introduction: The Fundamental Problems of Defectology. The Collected Works of LS Vygotsky, 2, 29-51.

World Health Organization (WHO). https://www.who.int/news-room/fact sheets/detail/deafness-andhearing-loss

Wiley, T. G. (2014). Diversity, Super-diversity, and Monolingual Language Ideology in the United States: Tolerance or Intolerance? Review of Research in Education, 38(1), 1-32.

\section{Appendix}

\section{A quick lesson on terminology - by Molly}

We asked our participant, a hearing instructor of ASL who has been teaching ASL at a community college for the past 13 years, to educate us on appropriate terminology and their differences. This is what she taught us:

Hard-of-Hearing and Deaf are completely separate terms. There are so many different terms that often get used interchangeably but are not often correct.

Deaf (with a capital D) refers to the Deaf community, people who are proud of their culture and their language (ASL in America), and do not consider themselves disabled. This term is used for any kind of hearing loss (profoundly deaf all the way to a very mild hearing loss). It doesn't really have anything to do with the amount of hearing someone has or doesn't have - it has to do with identity. However, even though I am fluent in ASL and very familiar with Deaf culture, I cannot be Deaf because I don't have any hearing loss. Just because someone identifies themselves as Deaf doesn't mean they can't speak.

deaf (with a lowercase d) - refers to the medical term that a doctor might use. This only signifies that a person has a severe or profound hearing loss and cannot hear. It does not tell us anything about their identity, or culture, or if they choose to use ASL or spoken language. Some profoundly deaf people can access speech through technology (hearing aids or cochlear implant), so they may not use sign language.

Hard-of-Hearing - this term is mostly used as a medical term too. It signifies a person with a mild to moderate or even moderate/severe hearing loss. Many people who are hard-of-hearing are still able to access speech through technology (hearing aid or cochlear implant). Some people who are hard-of-hearing in the medical term identify themselves as Deaf in the cultural term.

Hearing Impaired - what the government and other agencies think is the PC way to address a person who has a hearing loss. The Deaf (cultural and linguistic) community finds this term offensive, as they do not think they are "impaired". 